\title{
Thinking from event of Kangtai hepatitis B vaccination
}

\author{
RUAN Li \\ Biotech Center for Viral Disease Emergency, Institute for Viral Disease Control and Prevention, Chinese Center for Disease Control and \\ Prevention, Beijing 102206, China
}

Received December 26, 2013; accepted January 31, 2014; published online February 12, 2014

Citation: Ruan L. Thinking from event of Kangtai hepatitis B vaccination. Sci China Life Sci, 2014, 57: 555-556, doi: 10.1007/s11427-014-4624-3

Hepatitis B is an infectious disease with serious health implications caused by hepatitis B virus. With blood, iatrogenic, sexual and mother-to-fetus transmission as its main transmission routes, hepatitis B virus causes diseases including acute or chronic hepatitis, liver cirrhosis and liver cancer. Most adults infected with hepatitis B virus can be healed, while infected infants may typically live with a chronic and persistent infection. According to the national survey of hepatitis B epidemics conducted in 1979, among all surveyed people, the mean carrier rate of hepatitis $\mathrm{B}$ surface antigen (HBsAg) was $9.76 \%$ and that children may reach or approximate the peak value when they are only four years old. According to a similar survey conducted in 1992, the mean carrier rate of HBsAg was $9.75 \%$, while for children, the peak of HBsAg-carrying rate was slightly reduced and delayed, indicating that the epidemic pattern has not changed much during 13 years. However, vaccination with hepatitis B vaccine in children initiated at the end of the 1980s has achieved a beneficial effect [1]. According to the national survey conducted in 2004, the HBsAg-carrier rate of adults was $7.18 \%$, and the mean carrier rate of children (1-4 years old) was reduced to $0.96 \%$, suggesting that hepatitis B vaccination, which was widely implemented in the 1990 s and incorporated into the immunization program in 2002, has achieved positive effects [2]. There is no doubt that it will continue to contribute to eliminating the harmfulness of hepatitis B to people's health, as long as the hepatitis $\mathrm{B}$ vaccine program is adhered to.

The hepatitis B vaccine is widely used in China since its

email: ruanl@bbn.cn successful development using blood resources in 1986.

Particularly, hepatitis B vaccines based on genetic engineering of $\mathrm{CHO}$ cells and yeast cells (introduced by the technical department of MERK) were introduced to the market in China in 1992 and 1996, respectively. China promoted the replacement of blood resource hepatitis B vaccines with hepatitis $B$ vaccines based on energetic engineering in 2000 and the incorporation of hepatitis vaccines into the program of immunization vaccination in 2002. The hepatitis B vaccine based on energetic engineering currently uses two cell types: (i) yeast (made in China or imported) and (ii) mammalian cells. The hepatitis B vaccine based on genetic engineering of yeasts (made in China) has been dominantly used for immunization vaccination [3]. With a high annual manufacturing quantity (under approval), of 100 million to 200 million dosages, the hepatitis $\mathrm{B}$ vaccine based on genetic engineering has been manufactured and administered for 20 years in China. Furthermore, it has been used as a preventative vaccination for at least 200 million infants, from which a large quantity of practical data and experience has been accumulated. Therefore, in general, the hepatitis B vaccine just mentioned is characterized by advanced techniques, stable processes and controllable quality and is safe and effective.

The event that "several infants are dead owing to the use of hepatitis B vaccine manufactured by Kangtai Company" is a serious issue that has provoked a reflection regarding the underlying issue of vaccination management (the issue related to the quality of the Kangtai vaccine is excluded in this paper as it is waiting to be examined by the corresponding drug supervision department). One distinctive 
feature of the event is that it was first reported by the civil media, and the official response only occurred one week after the death cases reported increased from 2 to 7 [4]. This has caused discussion regarding the use of preventative vaccination and the influence of the event is now far beyond that of the event itself. Undoubtedly, it is now necessary and urgent for us to think about the underlying issues of prevention vaccination.

First, this event demonstrates that the Chinese vaccine adverse reaction monitoring and reporting system is incomplete and therefore it is necessary to revise the reporting system to enhance accurate monitoring, sensitive reactions and timely handling, so that we can react quickly when adverse reactions occur, whether the vaccine is new or old. This action should be faster, more accurate, more scientific and more powerful than the private media.

Second, it is necessary to set up a database of vaccination adverse reactions. Statements should be made on the basis of science to handle adverse events properly. In China, there are more than 30 kinds of vaccines, and a database of vaccination adverse reactions can provide data support for deciding and handling adverse reactions. For example, hundreds of millions of hepatitis $B$ vaccinations have been produced and hundreds of millions of people have been vaccinated. If these are produced to a certain scientific product quality and a database of vaccination adverse reactions is established then when a problem occurs, a reasona- ble scientific explanation may be given to the public from both the company and government.

Third, it is an important guarantee to setup a compensation system for serious vaccine adverse reactions. This compensation system should be included in the informed consent of individuals being vaccinated.

Finally, with the improvement of living standards, hygiene standards and health care standards, the hepatitis B plan immunization program can also be altered on a research basis. For example, we should consider whether the provision that infants must receive a hepatitis $\mathrm{B}$ vaccine within $24 \mathrm{~h}$ after being born need to be changed. However, infants who are hepatitis B surface antigen and/or E antigen positive must receive hepatitis $\mathrm{B}$ vaccine within $24 \mathrm{~h}$ after being born.

1 Liu CB. Epidemiology of viral hepatitis B. In: Liu XG, Qi ZB, Xiong SS, eds. The Laboratory Diagnosis of Viral Hepatitis. 2nd ed. Beijing: People Health Publication, 1999. 107-110

2 Bureau of Disease Control and Prevention of Ministry of Health of China and Chinese Center for Disease Control and Prevention. Report of Seroepidemiology Survey of Viral Hepatitis B in China. Beijing: People Health Publication, 2011

3 Ruan L. Genetic engineering subunit vaccine. In: Zhao K, ed. Vaccine. Beijing: People Health Publication, 2013. 396-400

4 China Food and Drug Administration and National Health and Family Planning Commission of the People's Republic of China. Media Briefing on the Event of Hepatitis B Vaccination. http://www. sfda.gov.cn/WS01/CL0051/95394.html, 24 Dec 2013

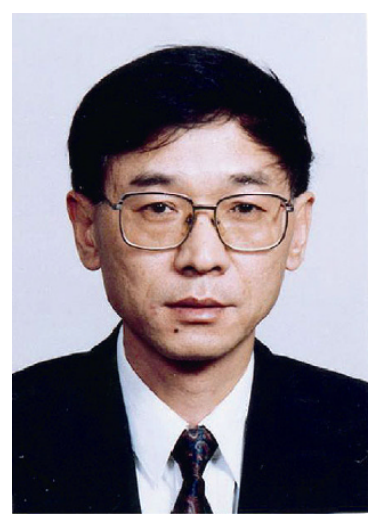

\section{Biographical Sketch}

As a doctor and researcher, Ruan Li once held the post of director of Institute for Viral Disease Control and Prevention of Chinese Centre for Disease Control and Prevention and chief of Biotech Center for Virus Disease Emergency. Since 1980, he has focused on the study of heritable variation and immunization of viruses and engaged in the research and development of biological technology including genetically engineered vaccines. In recent years, he was responsible for the monitoring of SARS and prevention and control of poxvirus related diseases such as smallpox and monkeypox. He was also responsible for over 20 research projects sponsored by national science and technology projects, national high-tech research and development plan, major sci-tech project, natural science fund, American NIH, EU and Ministry of Health, amongst others. He established two genetic expression systems using mammalian cells and recombinant vaccinia virus Tiantan strain and successfully researched Hepatitis B genetic engineering vaccine and Phase I clinic trails of five vaccinia recombinant vaccines. He was awarded a certificate of distinguished visiting scientist at Mount Sinai School of Medicine, New York in 1986, a certificate of excellent returned overseas researcher who made outstanding contributions to the state in 1991, a government special allowance in 1991, the National Science Fund for Distinguished Young Scholars (NSFDYS) in 1995, the title of National Expert with Remarkable Contributions in 1996, the first prize of the National Science and Technology Progress in Recombinant Hepatitis B Vaccine Research in 1993 and the second prize of the National Science and Technology Progress in Research and Application of High-Efficiency Expression System Derived from Vaccinia Virus Tiantan Strain. He has also won other four provincial and ministry prizes, was involved in producing over 20 books, applied for 11 patents and published over 200 papers.

Open Access This article is distributed under the terms of the Creative Commons Attribution License which permits any use, distribution, and reproduction in any medium, provided the original author(s) and source are credited. 